\title{
COMPARISON BETWEEN INVESTIGATION TECHNIQUES FOR THE EVALUATION OF THE COMPRESSIVE PROPERTIES OF BRICK MASONRY STRUCTURES
}

\author{
FRANCESCA FERRETTI $^{1 *}$, ANDREA INCERTI ${ }^{2}$ AND CLAUDIO MAZZOTTI ${ }^{1}$ \\ ${ }^{1}$ Department of Civil, Chemical, Environmental and Materials Engineering (DICAM) \\ University of Bologna, Italy \\ Viale Risorgimento 2, 40136 Bologna, Italy \\ e-mail: \{francesca.ferretti10, claudio.mazzotti\}@unibo.it,www.dicam.unibo.it \\ (*corresponding author) \\ ${ }^{2}$ CIRI Buildings \& Construction (CIRI-EC) \\ University of Bologna, Italy \\ Via del Lazzaretto 15/5, 40131 Bologna, Italy \\ email: a.incerti@unibo.it,www.edilizia-costruzioni.unibo.it
}

Keywords: Brick Masonry, Compressive Behavior, Slightly-Destructive Testing, Double Flatjack Test, Core Testing

\begin{abstract}
Existing masonry buildings, representing a large portion of the building stock in the Mediterranean area, are usually characterized by the presence of different constituent materials. The modifications experienced over time could have modified the static configuration of the structures and could trigger local damages and crises. Therefore, it is of fundamental importance to assess the safety of these constructions and to determine if retrofitting interventions are needed. In this framework, one of the crucial aspects is the mechanical characterization of masonry. Concerning brick masonries, several testing methodologies exist for the determination of the compressive strength, the elastic modulus and the Poisson's ratio. In particular, slightly-destructive tests, such as double flatjack tests and compressive tests on masonry cores, can be performed in place of destructive tests due to their limited invasiveness. However, they could be less representative of the overall behavior of masonry structural elements. The objective of the research is to evaluate the reliability of slightly-destructive tests in evaluating the compressive properties of masonry. An experimental campaign is presented, in which masonry specimens were built to reproduce a poor-quality brick masonry typology. Standard compression tests on wallets and double flatjack tests, both monotonic and cyclic, were performed. Moreover, masonry cores were extracted from the masonry specimens and tested in compression. Compressive strength, elastic modulus and Poisson's ratio were evaluated from each testing methodology. The results obtained from the double flatjack tests and the tests on cores, in terms of strength and deformability properties, were compared with the results of the standard compression tests, taken as reference. Correlations between the results of the slightly-destructive tests and the standard compression tests were established, obtaining a good agreement and confirming that the experimental techniques can be reliably adopted for the evaluation of the compressive properties of brick masonry.
\end{abstract}




\section{INTRODUCTION}

Existing masonry buildings, which represent a large portion of the building stock in the Mediterranean area, are usually characterized by the presence of different constituent materials, whose quality often depended on the final use of the constructions [1]. The variations that existing buildings experienced over time, such as changes regarding the acting loads or the environmental conditions, could have modified the static configuration of the structures and could trigger local damages and crises. Therefore, it is of fundamental importance to assess the safety of these constructions and to determine if some retrofitting intervention is needed.

In the framework of the vulnerability assessment procedures, one of the most important aspects is the mechanical characterization of the materials. For what concerns the compressive behavior of brick masonry structural elements, the masonry can be characterized as a composite or starting from the mechanical properties of the constituents, i.e. bricks and mortar. Moreover, different testing methodologies can be adopted and, in general, it is possible to distinguish between non-destructive, slightly-destructive and destructive procedures [2]. When dealing with existing masonries, the level of invasiveness of the experimental investigations on the construction should be possibly limited. Therefore, usually the execution of slightly-destructive tests is preferred to the execution of destructive tests.

For the determination of the compressive properties of masonry, in terms of compressive strength, elastic modulus and Poisson's ratio, some slightly-destructive tests can be performed, such as double flatjack tests $[3,4]$ and compression tests on masonry cores [5]. Even if these

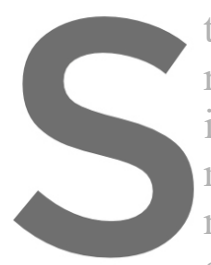
tests are characterized representative of the ov investigated the reliabili masonry [6-8]. More in detail non-standard technique geometry of the mortar capping and the diment
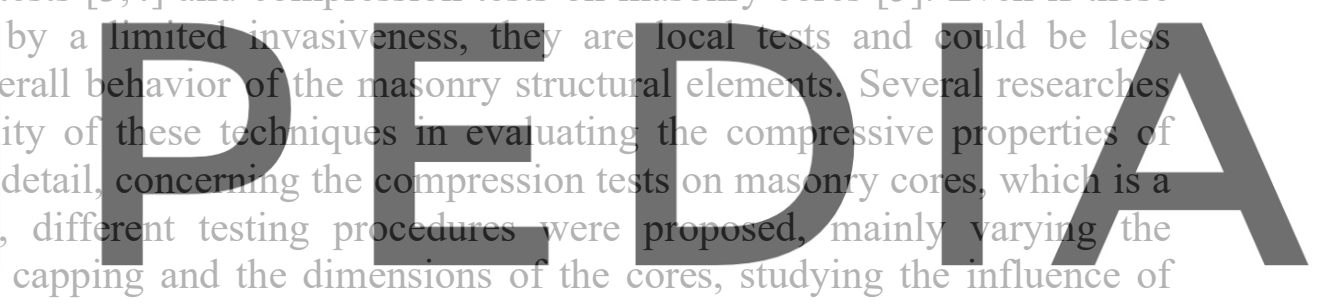
different bond patterns, i.e. presence of both vertical and horizontal joints. The research here

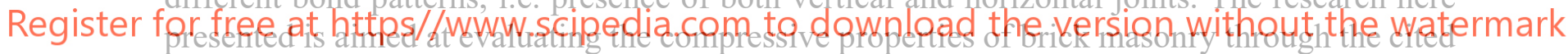
slightly-destructive tests and, eventually, at establishing correlations between the results of these tests and the standard compression tests.

\section{MATERIALS AND METHODS}

In the present experimental campaign, slightly-destructive tests were performed for the determination of the compressive properties of brick masonry, i.e. compressive strength, elastic modulus, Poisson's ratio. More in detail, double flatjack tests and compressive tests on cores were performed and the results were compared with the ones from standard compression tests on wallets, taken as reference. The tests were conducted in laboratory on replicated clay brick masonry samples whose properties are described in the following.

\subsection{Brick Masonry}

The replicated samples were built using fired clay bricks, with dimensions $250 \times 120 \times 55$ $\mathrm{mm}^{3}$, and natural hydraulic lime-based mortar; specimens were cured in a laboratory-controlled environment [9]. The mortar mix was designed to obtain a poor-quality mortar with the objective of reproducing an existing historical masonry. Standard laboratory tests [10-13] were 
performed on the constituent materials for their mechanical characterization. The results are reported in Table 1 , in terms of compressive strength $\left(f_{c}\right)$, flexural strength $\left(f_{f}\right)$, elastic modulus $(E)$.

Table 1: Mechanical properties of the constituent materials

\begin{tabular}{cccc}
\hline Material & $\begin{array}{c}f_{c} \\
(\mathrm{MPa})\end{array}$ & $\begin{array}{c}f_{f l} \\
(\mathrm{MPa})\end{array}$ & $\begin{array}{c}E \\
(\mathrm{MPa})\end{array}$ \\
\hline Brick & 18.7 & 4.6 & 6846 \\
\hline Mortar & 1.4 & 0.4 & 2549 \\
\hline
\end{tabular}

\subsection{Standard Compression Test on Wallets}

For the execution of the compression tests on wallets, according to the Standard EN 1052-1 [14], four double-wythe masonry panels were built. They were characterized by dimensions equal to $710 \times 790 \times 250 \mathrm{~mm}^{3}$ and by a Flemish bond pattern. A universal testing machine, having a maximum capacity of $6000 \mathrm{kN}$, was used to apply the compression load to the panels. Two monotonic and two cyclic tests were performed. More in detail, the loading protocol of the cyclic tests was defined to progressively apply the $20 \%, 40 \%, 60 \%, 80 \%$ and $100 \%$ of the maximum load, as evaluated from the monotonic tests. A further load cycle was performed after the reaching of the peak load. The wall panels were equipped with vertical and horizontal linear

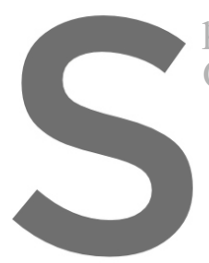
potentiometers to monitor their
Correlation was also used on d
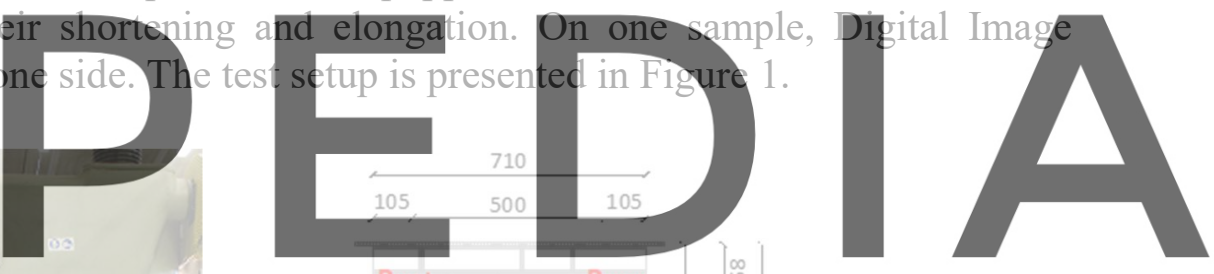

Register for free at https//www.scipedia.com to download the version without the watermark
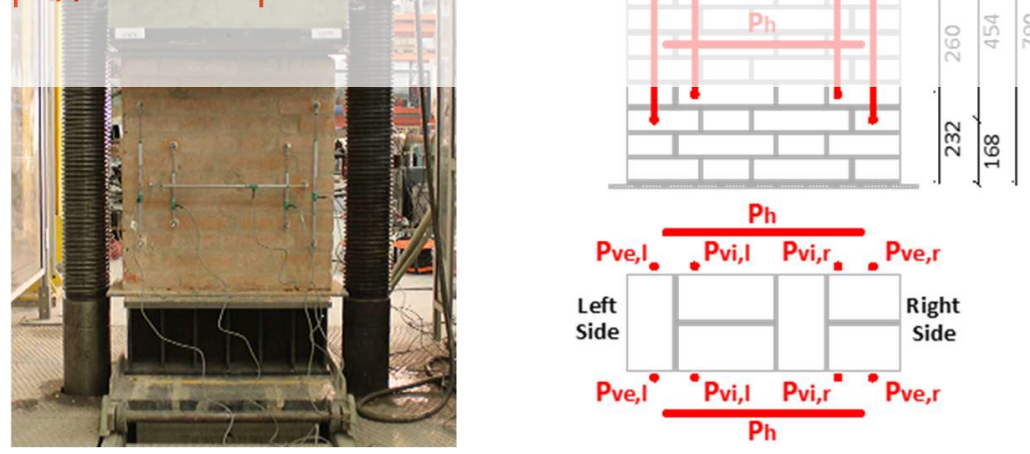

Figure 1: Compression test on wallets: test setup

\subsection{Double Flatjack Test}

The double flatjack tests were conducted on two masonry panels, having dimensions $1290 \times 1115 \times 250 \mathrm{~mm}^{3}$, according to the Standard ASTM C1197 [3]. The purpose was to reproduce the execution of a double flatjack test in an existing masonry building. For this reason, the universal testing machine used for the standard compression tests on wallets was 
adopted to apply a uniform compression on the masonry panels, reproducing the acting dead loads, and to provide the contrast needed for the correct execution of the double flatjack test. Indeed, it is well known that one of the possible issues of the test is not to have a sufficient contrast over the superior flatjack, thus producing the uplift of the masonry portion above the superior cut.

The testing phases can be summarized as follows: (i) execution of two semicircular cuts in correspondence of two masonry joints of the wall panels; (ii) seating of the flatjacks; (iii) application of a uniform compressive stress equal to $0.2 \mathrm{MPa}$; (iv) application of the flatjack pressure. During the last phase, the displacements of the plates of the testing machine were fixed, so to provide the contrast to the pressure applied by the flatjacks. Of course, having an increasing contrast pressure, equilibrating the flatjack pressure, is not a real condition when the test is performed on an existing masonry building. However, it is here considered so to allow to reach the compressive failure of the masonry portion between the flatjack and to compare the results with the standard compression tests. Moreover, the redistribution capacity of the masonry beyond the flatjacks, i.e. outside the tested portion, can be much lower if compared to an existing masonry pier, due to the smaller dimensions of the masonry panels in the present experimental campaign. This could determine even a more probable occurrence of the failure of masonry outside the tested area. For these reasons, it was decided to fix the displacements of the loading plates to provide an adequate contrast pressure for the entire duration of the tests.

At the beginning of the tests, one initial cycle was conducted to seat the flatjacks up to a pressure equal to half of the estimated compressive strength of masonry. Subsequently, the
pressure was applied monotonically or cyclically up to the compressive tailure of the masonry
portion between the flatjacks. For the cyclic test, the loading protocol adopted for the standard
compression tests was used.
For the measurements of the vertical and horizontal displacements within the tested masonry
portion, linear potentioneters were applied over the surface of the samples, on both sides, as shown in Figure 2. Moreover, two linear potentiometers were also installed laterally to monitor

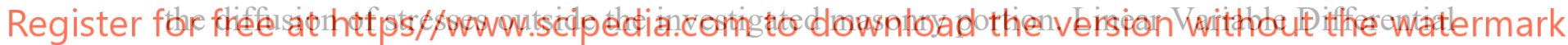
Transducers (LVDT) were used to control the displacements of the loading plates.
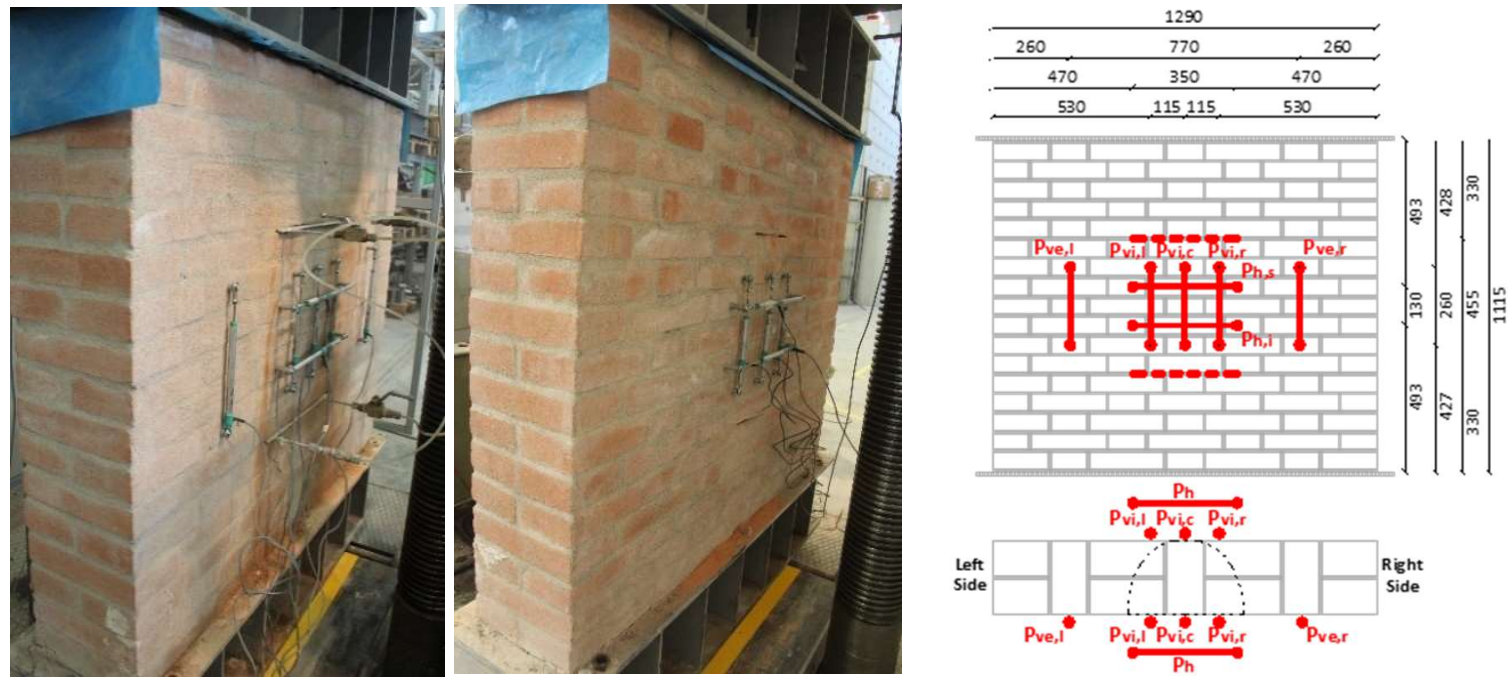

Figure 2: Double flatjack tests: test setup 


\subsection{Compression Test on Cores}

Masonry cores were extracted from one of the masonry panels on which the double flatjack test was performed through a wet coring procedure. The samples were taken from the masonry portions resulted undamaged after the tests. Two different types of cores, having a diameter equal to $100 \mathrm{~mm}$, were chosen: (i) 6 samples including one horizontal joint only ( $H J$ samples, Figure $3 a$ ); (ii) 5 samples including both one horizontal and one vertical joint ( $V J$ samples, Figure $3 b$ ). After the extraction procedure, the cores were cut to obtain single-wythe samples. To apply a compressive load and provide an adequate confinement to the samples, the masonry cores were capped with a good-strength mortar, characterized by a compressive strength equal to $22 \mathrm{MPa}$. The geometry of the cap, with a width equal to $80 \mathrm{~mm}$ and a height of $30 \mathrm{~mm}$, was chosen according to previous studies $[5,6]$.

The compression tests were performed in displacement control, using a hydraulic actuator having a maximum capacity of $100 \mathrm{kN}$. The displacement rate was equal to $0.02 \mathrm{~mm} / \mathrm{s}$. During the tests, vertical displacements were monitored using LVDTs, positioned on both sides of the masonry cores, as shown in Figure 4.
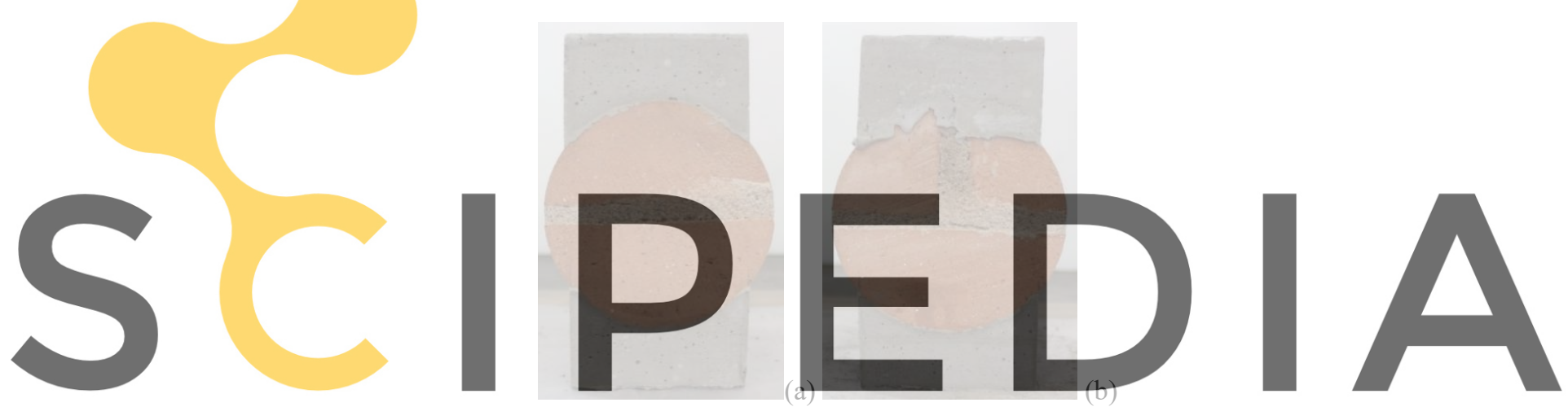

Figure 3: Core samples: (a) type $H J$; (b) type $V J$

Register for free at https//www.scipedia.com to download the version without the watermark
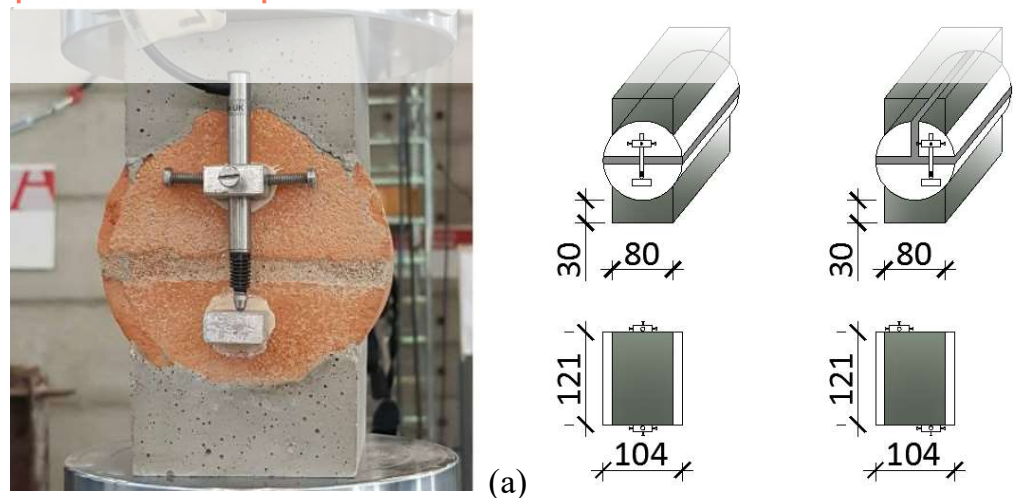

(b)

Figure 4: Compression tests on cores: (a) experimental setup; (b) geometry and instrumentation

\section{EXPERIMENTAL RESULTS}

\subsection{Standard Compression Tests on Wallets}

The results of the standard compression tests are reported in Table 2 in terms of compressive 
stress at first cracking $f_{c r}$, compressive strength $f_{M}$, elastic modulus $E_{M}$ and Poisson's ratio $v$. The elastic modulus $E_{M}$ was determined between $1 / 10$ and $1 / 3$ of the maximum stress registered. Inside this range, the behavior of masonry can be reasonably assumed to be linear elastic. The Poisson's ratio $v$ was evaluated in the initial linear elastic stage as well, in which a constant value was identified. For cyclic tests, the elastic properties were evaluated in each load cycle, showing a stiffness degradation as expected. The values reported in Table 2 represent the average values determined by considering the reloading branch of each cycle with the exception of the last cycles, in which the nonlinear behavior was evident. It can be observed that the experimental results are quite homogeneous, with no significant differences between monotonic and cyclic tests.

In general, a similar behavior was observed for the masonry panels tested. It was characterized by a first vertical cracking, located at the center of the samples, visible on both sides. Subsequently, further vertical cracks appeared, quite distributed over the panels. At the end of the tests, a vertical crack across the wall thickness occurred (Figure 5).

The stress vs strain curves obtained for the samples SCT_M1 and SCT_M3, representative of a monotonic and a cyclic test, respectively, are reported in Figure 6 and Figure 7. As expected (Figure $6 a$ ), the displacements measured by the external potentiometers $\left(P_{v e}\right)$ were lower than the ones registered by internal potentiometers $\left(P_{v i}\right)$. The external instruments were positioned to better monitor the behavior of the samples, but they were not considered for the determination of the mechanical properties, e.g. $E_{M}, v$. Moreover, the behavior of the panel SCT_M1 was

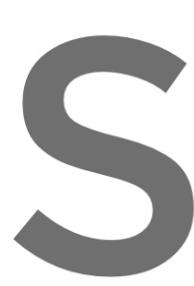
investigated by means maps reported in Figur corresponding to the appearan

Register for free at ht+fost
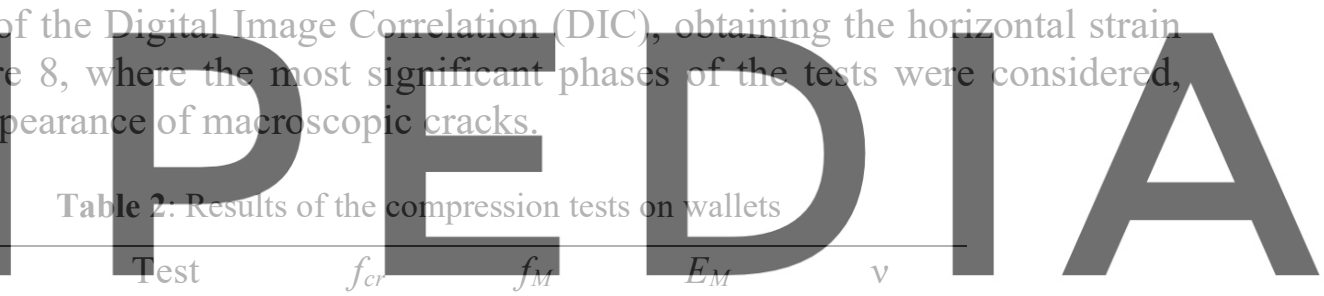

Type $(\mathrm{MPa})$

$(\mathrm{MPa})$

$(\mathrm{MPa})$

$(-)$

\begin{tabular}{lccccc} 
SCT_M2 & Monotonic & 1.7 & 6.3 & 2974 & 0.19 \\
\hline SCT M3 & Cyclic & 1.1 & 6.7 & 3656 & 0.15 \\
\hline SCT_M4 & Cyclic & 2.1 & 6.1 & 2832 & 0.20 \\
\hline
\end{tabular}
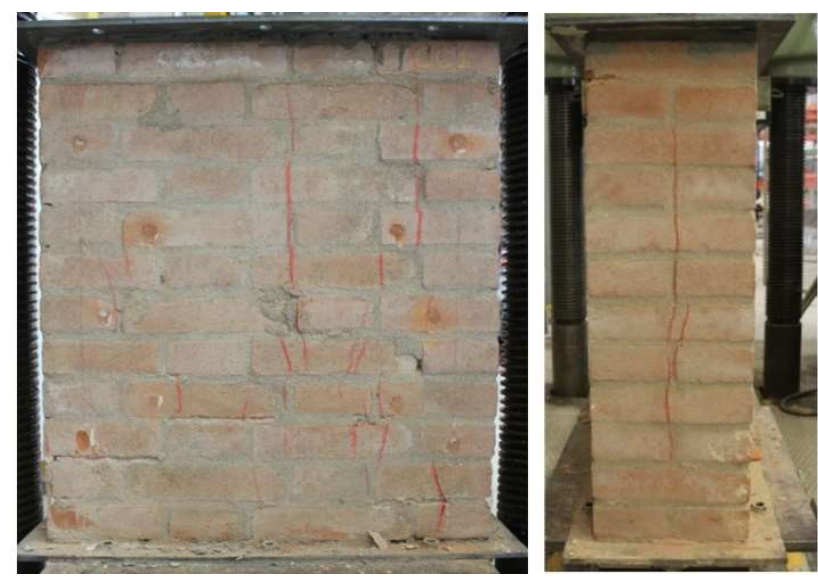

Figure 5: Compression test on wallets: failure mode of the sample SCT_M1. 

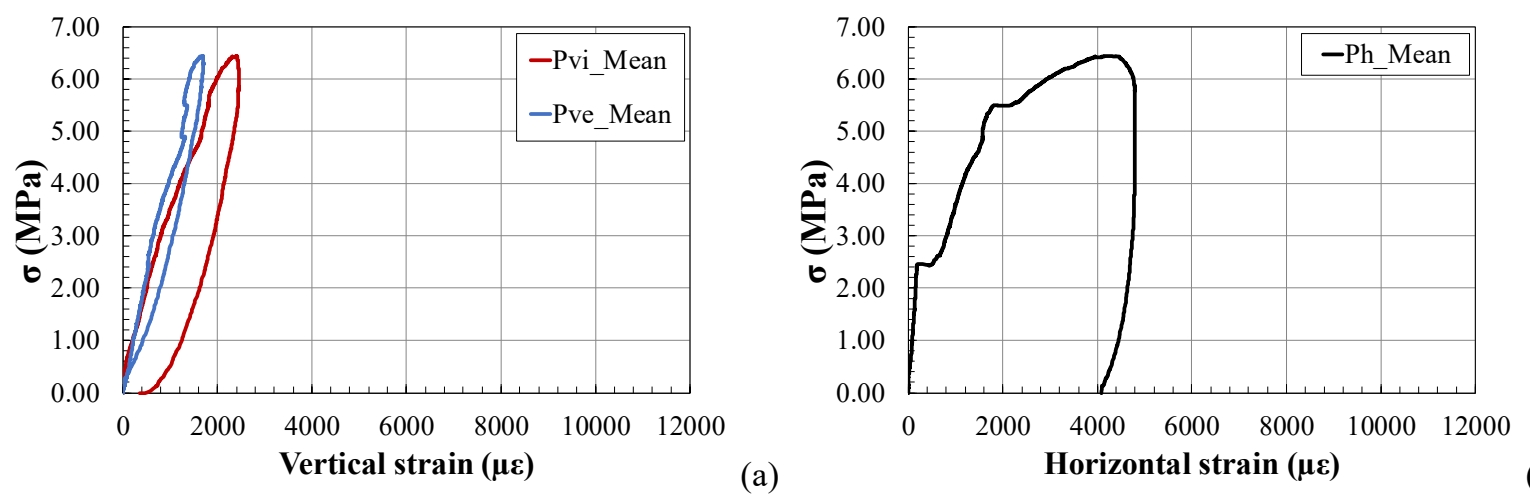

(b)

Figure 6: Stress vs vertical (a) and horizontal (b) strain diagrams of the sample SCT_M1
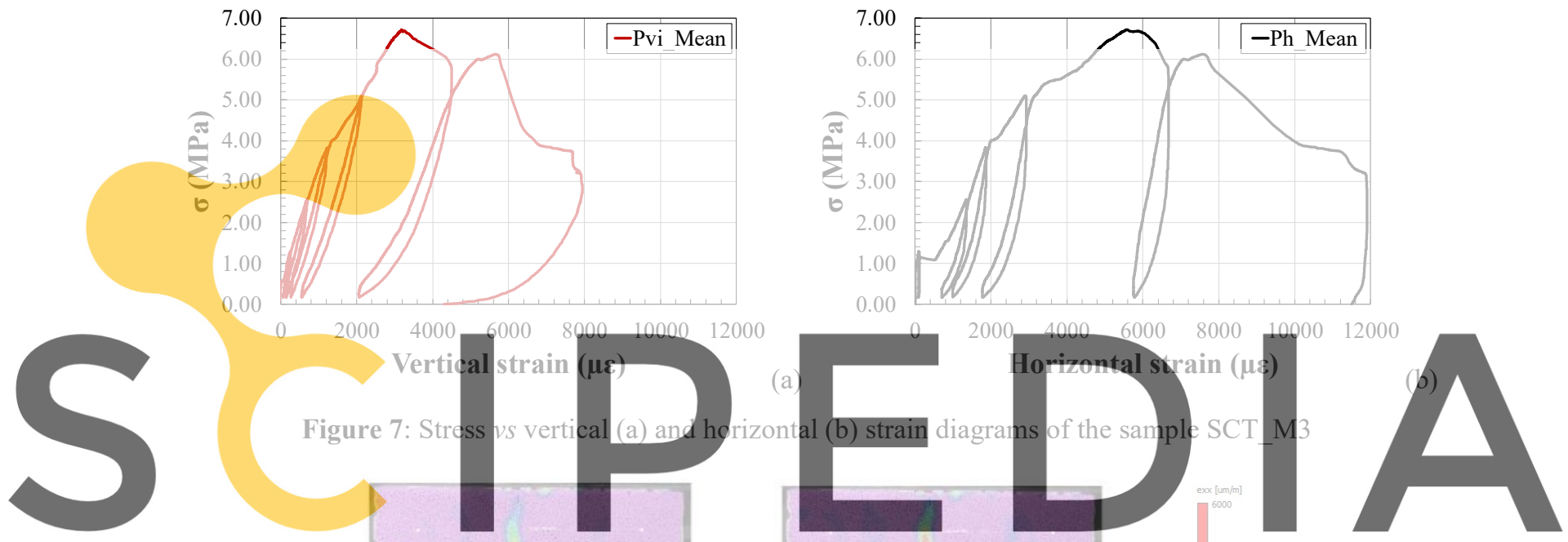

Register for free at https//www.scipedia.com to download the version without the watermark
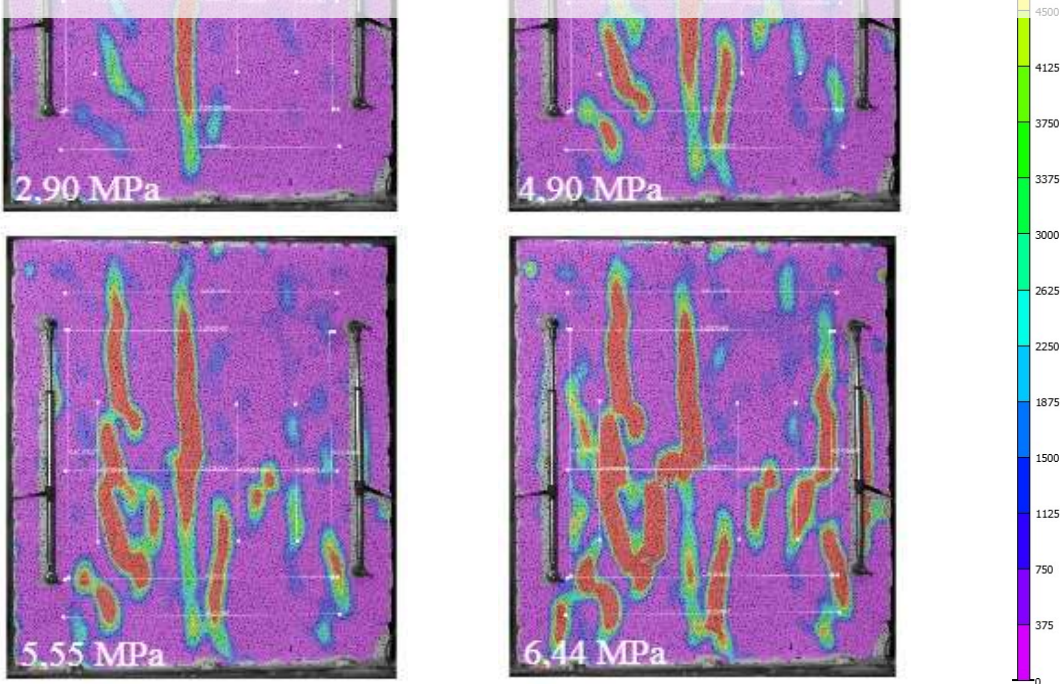

Figure 8: Compression test on wallets: horizontal strain maps of the sample SCT_M1. 


\subsection{Double Flatjack Test}

The results of the double flatjack tests are reported in Table 3 in terms of compressive stress at first cracking $f_{c r}$, compressive strength $f_{M}$, elastic modulus $E_{M}$ and Poisson's ratio $v$. The elastic properties of the masonry were determined as described for the standard compression tests on wallets, considering the instruments positioned on the front side of the panel, i.e. the side from which the cuts were executed, within the tested masonry portion. In Table 3, the calibration constant $k_{m}$ of the flatjack and the constant $k_{a}$, determined as the ratio of measured area of the flatjack to the average measured area of the slot, are also reported. According to the Standard [3], by multiplying the pressure of the flatjack and these constant, the stress on the tested portion can be evaluated at each instant of the test.

The failure mode of the two samples was similar (Figure 9), with vertical cracks located in the masonry portion between the flatjacks and inclined cracks outside this region, e.g. following a diagonal path from the edges of the flatjacks to the loading plates of the machine. This was, indeed, able to provide a sufficient contrast, even if at the end of the test, with quite high values of the flatjack pressure, horizontal cracks appeared in correspondence of the cuts.

The stress $v s$ strain diagrams are reported in Figure 10 for both samples. In particular, it is possible to recognize the stress associated to the first cracking $\left(f_{c r}\right)$. From this point on, the horizontal deformations progressively increased. In the cyclic test (DFJ M2), a lower compressive strength was obtained, while a stiffness degradation was not recognizable, except from the last load cycle.
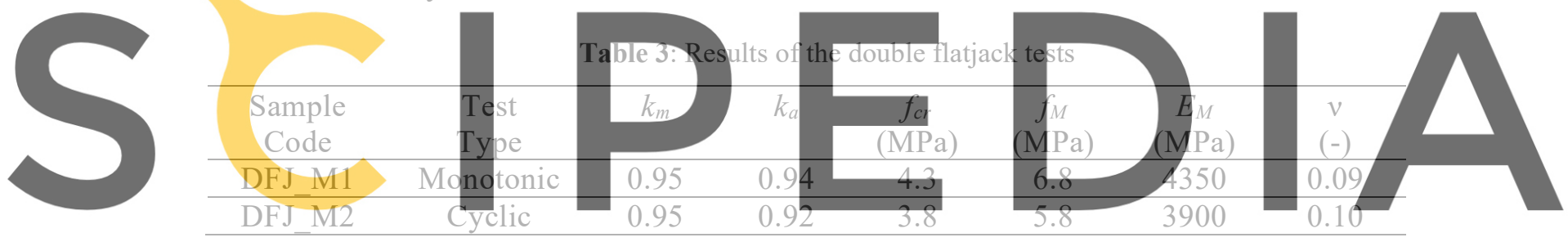

Register for free at https//www.scipedia.com to download the version without the watermark

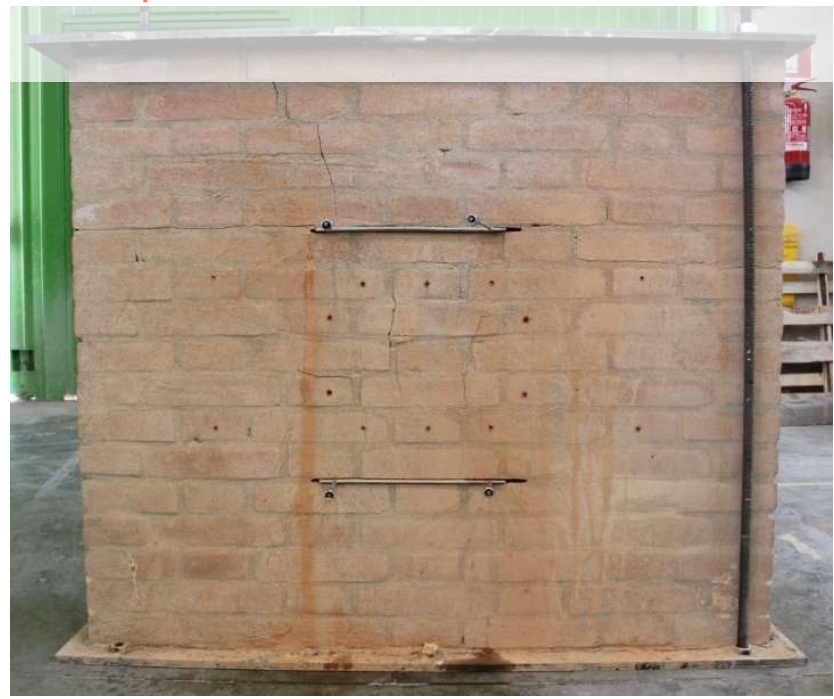

Figure 9: Double flatjack test: failure mode of the sample DFJ_M2 

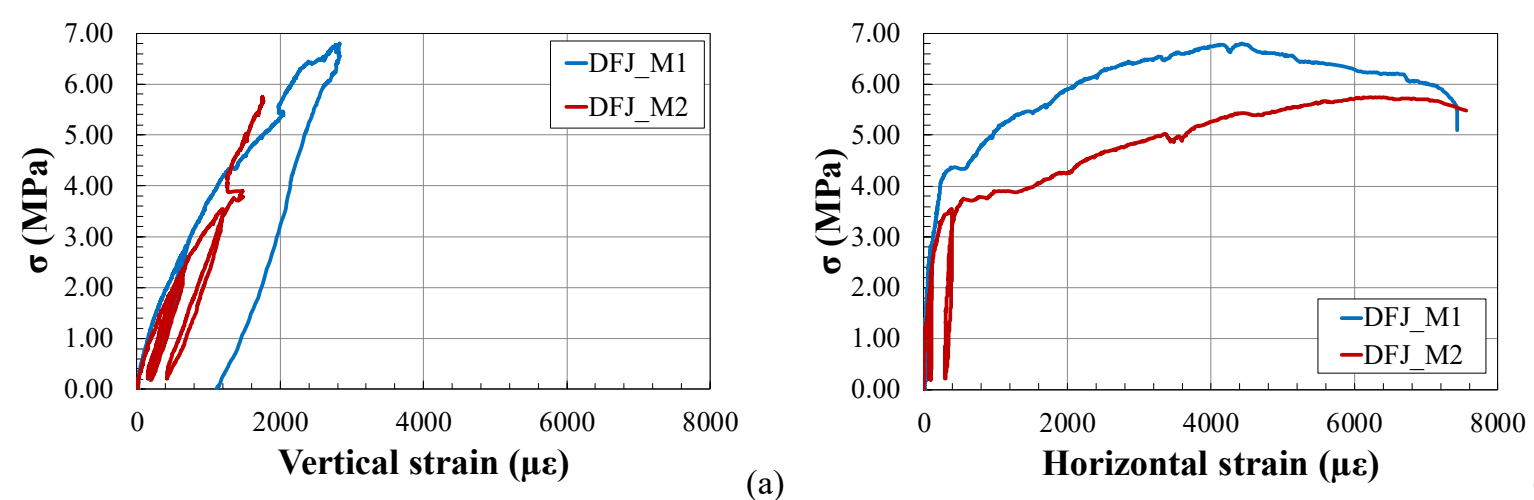

(a)

(b)

Figure 10: Stress vs vertical (a) and horizontal (b) strain diagrams of the double flatjack tests

\subsection{Compression Test on Cores}

The results of the compression tests on cores are presented in Table 4, in terms of compressive stress at first cracking $f_{c r}$, compressive strength $f_{M}$ and elastic modulus $E_{M}$. The Poisson's ratio $v$ was not determined since only vertical potentiometers were applied to the samples.

Table 4: Results of the compression tests on cores
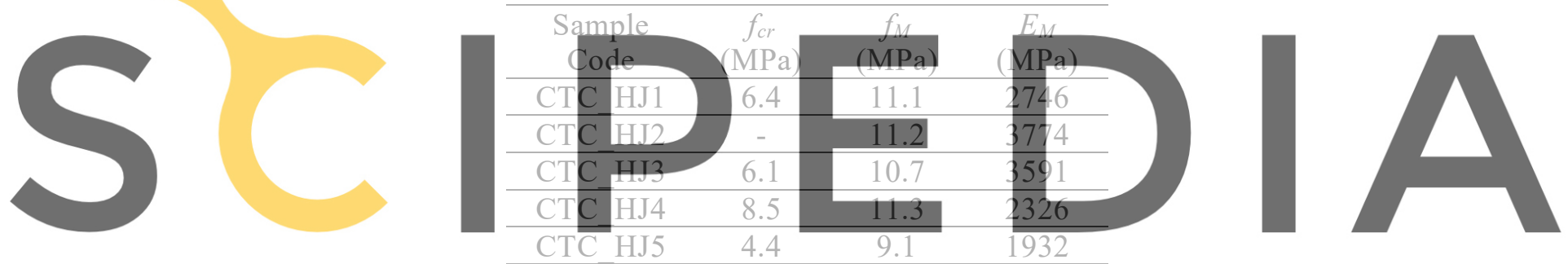

Register for free at https//www.\$Gipedja.com5.to downbload the 10.78 yersion without the watermark

\begin{tabular}{cccc}
\hline $\mathrm{CTC}$ _VJ2 & 7.9 & 11.1 & 2668 \\
\hline $\mathrm{CTC}$ _VJ3 & 2.6 & 7.5 & 1173 \\
\hline $\mathrm{CTC}$ _VJ4 & 6.8 & 8.1 & 1130 \\
\hline $\mathrm{CTC}$ _VJ5 & 6.7 & 8.5 & - \\
\hline
\end{tabular}

With reference to the failure mode of the cores, a distinction should be made between the $H J$ samples and the $V J$ samples. Indeed, the presence of a vertical joint did influence the onset and the propagation of the failure. In general, the mortar capping was able to provide an adequate confinement to the samples, leading to the desired failure mode. More in detail:

- For $H J$ samples (Figure 11a) the first vertical crack was located in the center of the samples, starting close to the mortar bed joint and propagating vertically; subsequently, several cracks appeared and, at the end of test, vertical cracks were visible also in correspondence of the edges of the mortar capping, where the confinement was lower.

- For $V J$ samples (Figure 11b) the cracking process started in correspondence of the vertical joint, at the mortar-to-brick interface; it then propagated towards the extremities of the cores. At the end of the tests, multiple cracks were visible, spread over the entire 
surface of the samples, even in correspondence of the edges of the mortar capping.

The stress $v s$ vertical strain diagrams reported in Figure 12 are representative of the compressive behavior of the $H J$ and $V J$ samples. In general, it can be stated that lower compressive strength and elastic modulus were obtained for the cores characterized by the presence of the vertical mortar joint ( $V J$ samples).
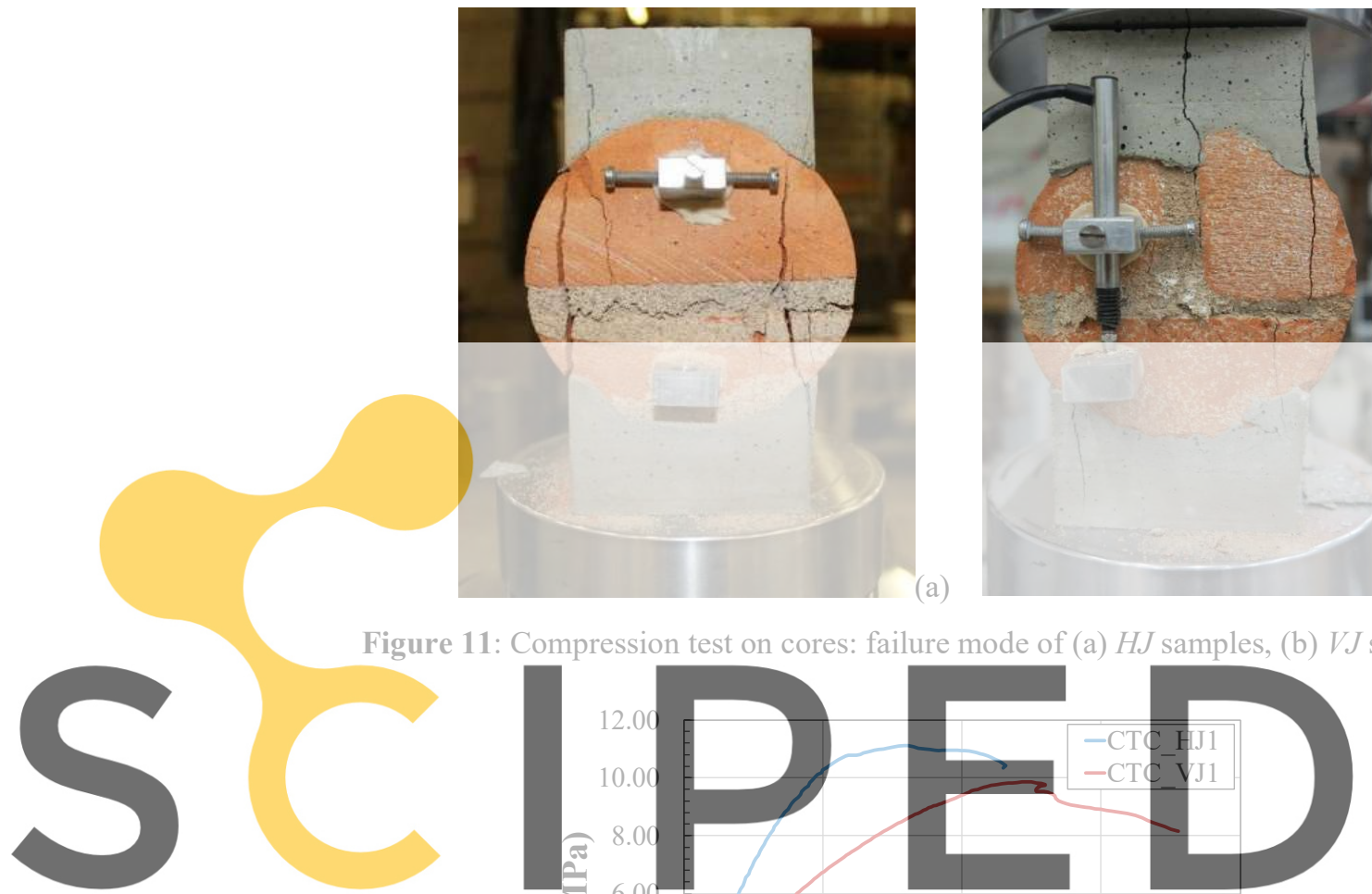

Figure 11: Compression test on cores: failure
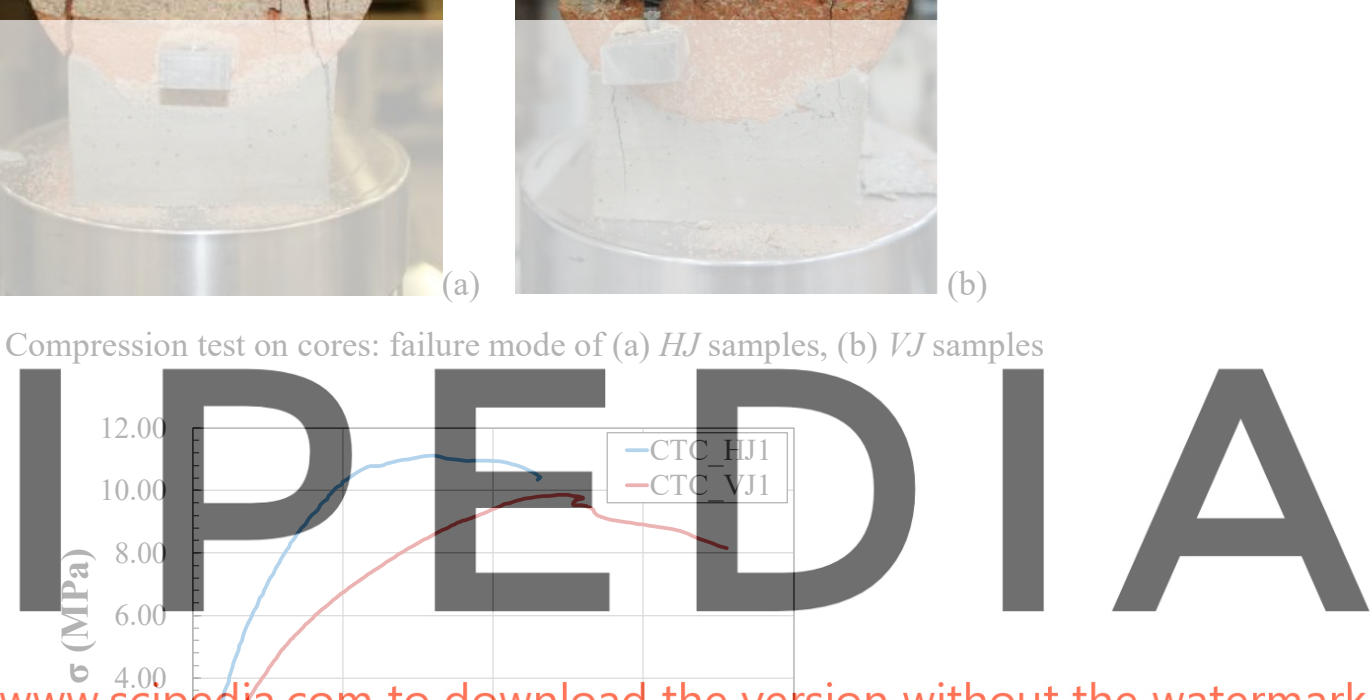

Register for free at https//www.scipedia.com to download the version without the watermark
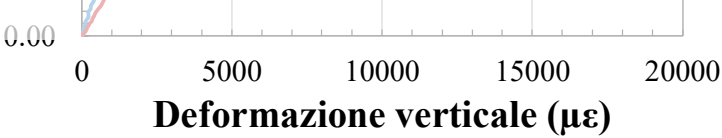

Figure 12: Stress vs vertical strain diagrams from the compression tests on cores

\section{DISCUSSION}

In this Section, the comparisons between the results of the different experimental tests are presented. In Table 5, the average values of the mechanical properties obtained with each testing methodology are reported.

A good agreement was obtained by comparing the results from the double flatjack tests and the results of the standard compression tests, taken as reference, especially for what concerns the masonry compressive strength $f_{M}$. A stiffer behavior was observed during the double flatjack tests, associated to higher $E_{M}$ and lower $v$ values, which can be probably related to the smaller dimensions of the tested masonry portion and to the fact that the masonry within the flatjacks was more confined laterally with respect to the masonry wallets. 
With reference to the compression tests on masonry cores, higher strength values were obtained, as expected, given that this test is a local test and that the mortar capping provides a strong confinement to the samples [5]. The results obtained by testing cores, overestimated the compressive strength of masonry by $67 \%$ and $43 \%$ for $H J$ samples and $V J$ samples, respectively. The values of the elastic modulus from the compression tests on cores are significantly lower than the ones obtained from standard compression tests. This can be explained by considering that the gage length of the vertical potentiometers is short and include small brick portions and one mortar joint, the latter significantly influencing the deformability of the samples.

The obtained results were also compared with the formula provided by the Eurocode 6 (EC6) for the evaluation of the masonry compressive strength. For this purpose, besides the standard compression tests described in Section 2.1, mortar samples extracted from the bed joints of the tested wall panels were subject to double punch test [15], obtaining an average compressive strength equal to $6.8 \mathrm{MPa}$. This value is significantly higher than the one obtained from the standard laboratory tests reported in Table 1. Such a difference can be attributed to the very different curing conditions of the mortar in the bed joints of the wall panels compared to the mortar standard prismatic specimens used for the mechanical characterization, as also confirmed by other researches on this topic [7]. By evaluating the masonry compressive strength through the EC6 formula, the following values were obtained: 4.7 MPa, considering the result reported in Table 1, and 7.6 MPa, considering the double punch test result.

Table 5: Comparison of the results

\begin{tabular}{ccccc}
\hline Test & $\begin{array}{c}f_{c r} \\
(\mathrm{MPa})\end{array}$ & $\begin{array}{c}f_{M} \\
(\mathrm{MPa})\end{array}$ & $\begin{array}{c}E_{M} \\
(\mathrm{MPa})\end{array}$ & $\begin{array}{c}v \\
(-)\end{array}$ \\
\hline SCT & 1.8 & 6.4 & 3211 & 0.17 \\
\hline DFJ & 4.1 & 6.3 & 4125 & 0.09 \\
\hline CTC_HJ & 6.6 & 10.7 & 2871 & - \\
\hline CTC_VJ & 6.0 & 9.0 & 1720 & - \\
\hline
\end{tabular}

\section{CONCLUSIONS}

In the present work, different slightly-destructive tests were performed to evaluate the compressive properties of clay brick masonry samples. Standard compression tests, double flatjack tests and compression tests on cores were conducted. The results obtained from the double flatjack tests and the tests on cores, in terms of strength and deformability properties, were compared with the results of the standard compression tests, taken as reference. Correlations between the results of the slightly-destructive tests and the standard compression tests were established, obtaining a good agreement and confirming that the experimental techniques can be reliably adopted for the evaluation of the compressive properties of brick masonry.

Acknowledgements. This paper was supported by the PRIN 2017 research program of the Italian Ministry of Education, University and Research, project DETECT-AGING, grant N. 201747Y73L. Mr. Diiterihs Erra (Technical staff at CIRI Buildings \& Construction) and the master student Valeria Rocco are gratefully acknowledged for their work during the setup of the tests. 


\section{REFERENCES}

[1] Ferretti, F., Ferracuti, B., Mazzotti, C. and Savoia M. Destructive and minor destructive tests on masonry buildings: Experimental results and comparison between shear failure criteria. Constr. Build. Mater. 199:12-29. https://doi.org/10.1016/j.conbuildmat.2018.11.246.

[2] Binda, L., Saisi, A. and Tiraboschi, C. Investigation procedures for the diagnosis of historic masonries, Constr. Build. Mater. (2000) 14:199-233. https://doi.org/10.1016/S0950-0618(00)00018-0.

[3] ASTM C1197-14. Standard Test Method for In Situ Measurement of Masonry Deformability Properties Using the Flatjack Method. American Society of Testing Material (2014).

[4] Binda, L. and Tiraboschi, C. Flatjack test as a slightly destructive technique for the diagnosis of brick and stone masonry structures. Int. Journal for Restoration of Buildings and Monuments (1999):449-472.

[5] Sassoni, E., Mazzotti, C. and Pagliai, G. Comparison between experimental methods for evaluating the compressive strength of existing masonry buildings. Constr. Build. Mater. (2014) 68:206-219.

[6] Sassoni, E. and Mazzotti, C. The use of small diameter cores for assessing the compressive strength of clay brick masonries. J. Cult. Herit. (2013) 14S:e95-e101.6.

[7] Pelà, L., Canella, E., Aprile, A. and Roca, P. Compression test of masonry core samples extracted from existing brickwork. Constr. Build. Mater. (2016) 119:230-240.

[8] Jafari, S., Rots, J.G. and Esposito, R. Core testing method to assess nonlinear behavior of brick masonry under compression: A comparative experimental study. Constr. Build. Mater. (2019) 218:193-205.

[9] Incerti, A., Rinaldini, V. and Mazzotti, C. The evaluation of masonry shear strength by means of different experimental techniques: a comparison between full-scale and laboratory tests. International Brick \& Block Masonry Conference (IBMAC), CRC Press (2016), pp. 1645-1652.

[10] EN 772-1. Methods of test for masonry units - Part 1: Determination of compressive strength, European Committee for Standardization (2011).

[11] EN 12390-5:2009. Testing hardened concrete - Part 5: Flexural strength of test specimens, European Committee for Standardization (2009).

[12] EN 12390-13. Testing hardened concrete - Determination of secant modulus of elasticity in compression, European Committee for Standardization (2013).

[13] EN 1015-11:1999/A1:2006. Methods of test for mortar for masonry - Part 11: Determination of flexural and compressive strength of hardened mortar, European Committee for Standardization (2006).

[14] EN 1052-1:1998. Methods of test for masonry - Part 1: Determination of compressive strength, European Committee for Standardization (1998).

[15] Henzel, J. and Karl, S. Determination of strength of mortar in the joints of masonry by compression tests on small specimens. Darmstadt Concrete (1987) 2:123-136. 